\title{
O viver com a doença falciforme: percepção de adolescentes*
}

\section{Living with sickle cell disease: adolescent's perception}

\author{
Larissa Nascimento Marques ${ }^{1}$, Alessandra Cavalcanti A. Souza ${ }^{2}$, \\ Andrea Ruzzi Pereira ${ }^{3}$
}

http://dx.doi.org/10.11606/issn.2238-6149.v26i1p109-117

\begin{abstract}
Marques LN, Souza ACA, Pereira AR. O viver com a doença falciforme: percepção de adolescentes. Rev Ter Ocup Univ São Paulo. 2015 jan./abr.;26(1):109-17.

RESUMO: Este estudo transversal descritivo com abordagem quantitativa qualitativa teve como objetivo descrever e analisar a percepção de adolescentes sobre o viver com Doença Falciforme (DF); identificar e analisar quais os principais papéis ocupacionais destes adolescentes e a importância que atribuem aos papéis. Os dados foram obtidos pela Lista de Identificação de Papéis Ocupacionais, por caracterização sociodemográfica dos participantes e por uma entrevista semiestruturada, junto a sete adolescentes com DF, sendo os dados da entrevista submetidos à análise de conteúdo temático categorial e os dados da Lista de Identificação de Papéis Ocupacionais analisados por frequência absoluta e relativa. Conclui-se que o viver com a DF é rodeado de privações que ocorrem em vários espaços do cotidiano do adolescente e podem levá-lo a qualidade de vida insatisfatória, e repercussões negativas no futuro.
\end{abstract}

DESCRITORES: Anemia falciforme; Doença da hemoglobina SC; Adolescente; Terapia ocupacional.
Marques LN, Souza ACA, Pereira AR. O viver com a doença falciforme: percepção de adolescentes. Living with sickle cell disease: adolescent's perception. Rev Ter Ocup Univ São Paulo. 2015 jan./abr.;26(1):109-17.

ABSTRACT: This cross-sectional descriptive study with qualitative quantitative approach aims to describe and analyze the perception of adolescents about living with Sickle Cell Disease (SCD); identify and analyze which major occupational roles of these teens and the importance they attach to the roles. Data were obtained by Role Checklist, by sociodemographic characteristics of participants and a semi-structured interview guideline with seven adolescents with SCD. The interview data were submitted to content analysis thematic categorical and the Role Checklist was analyzed by absolute and relative frequency. We conclude that living with SCD is surrounded by hardships that occur in various spaces of daily lives of adolescents and may lead them to a unsatisfactory quality of life, and negative repercussions in the future.

KEYWORDS: Anemia, sickle cell; Hemoglobin SC disease; Adolescent; Occupational therapy.

\footnotetext{
* Resultado do Trabalho de Conclusão de Curso (TCC) do Curso de Terapia Ocupacional da Universidade Federal do Triângulo Mineiro (UFTM) aprovado pelo Comitê de Ética da UFTM de acordo com o parecer no 2012/11.

1. Terapeuta Ocupacional Home Care - Cuiabá, MT.

2. Prof ${ }^{\mathrm{a}}$ Assistente do Curso de Terapia Ocupacional da Universidade Federal do Triângulo Mineiro - UFTM.

3. Terapeuta Ocupacional Home Care - Cuiabá, MT.

4. Prof ${ }^{a}$ Assistente do Curso de Terapia Ocupacional da Universidade Federal do Triângulo Mineiro - UFTM.

Endereço para correspondência: Universidade Federal do Triângulo Mineiro. Unidade Centro Educacional (CE). Curso de Terapia Ocupacional. Núcleo de Ensino e Pesquisa em Saúde Mental, Álcool e outras Drogas - NEPSMAD. Av. Getúlio Guaritá, 159. Sala 329. $3^{\circ}$ Piso. Uberaba, MG. CEP: 38025-440. E-mail: nepsmad@gmail.com.
} 


\section{INTRODUÇÃO}

$\mathrm{D}$ oença crônica é qualquer doença que atinge uma pessoa interferindo em suas atividades diárias, provocando invalidez permanente ou residual, alteração patológica irreversível ou que requer longos períodos de supervisão, atenção e/ou reabilitação ${ }^{1}$. De acordo com Pitaluga ${ }^{2}$, as doenças crônicas são a principal causa de incapacidade, a maior demanda para serviços de saúde e respondem por parte considerável dos gastos efetuados no setor da saúde.

As doenças falciformes são doenças hematológicas de caráter crônico, genético e hereditário com altas frequências no Brasil e no mundo. Sua causa é uma mutação no gene da hemoglobina $\mathrm{A}$, originando uma hemoglobina alterada denominada S. A denominação "Anemia Falciforme" é reservada para a forma da doença que ocorre em homozigotos SS, mas o gene S pode combinar-se com outras alterações hereditárias das hemoglobinas como as hemoglobinas C, D, E e Beta Talassemia, entre outras, gerando combinações que também são sintomáticas. Apesar das particularidades que as distinguem e de graus variados de gravidade, todas essas doenças tem o perfil epidemiológico e de manifestações clínicas e hematológicas semelhantes ${ }^{3-5}$.

Em homozigotos (SS) as hemácias em vez de arredondadas sofrem falcização (apresentam-se em forma de foice, daí o nome falciforme) ocasionando encurtamento de sua vida média, fenômenos de vaso-oclusão (obstrução), episódios de dor, lesão de órgãos e anemia crônica ${ }^{4}$.

Essa mutação originou-se no continente africano e apresenta altas incidências na África, Arábia Saudita e Índia. No Brasil as doenças falciformes fazem parte do grupo de doenças e agravos que afetam a população afrodescendente ${ }^{3}$.

Há cerca de dois milhões de brasileiros portadores do gene da $\mathrm{HbS}$, sendo mais de 8.000 afetados com a forma homozigótica. Estima-se o nascimento de 3.500 novos casos anuais de doenças falciformes no país, caracterizando-as como problema de saúde pública ${ }^{6-7}$.

As primeiras manifestações clínicas das doenças falciformes ocorrem já nos primeiros meses de idade e perduram por toda a vida. Especialmente na adolescência, este caráter crônico associado à variabilidade clínica das doenças falciformes, pode representar alto grau de sofrimento e problemas de ajustamento, com dificuldades atribuídas às complicações físicas, clínicas e psicológicas de sua condição médica. Pode haver problemas com a autoimagem, o autoconceito e a autoestima, atribuídos ao retardo sexual, da maturação física e do crescimento, como também de sua aparência, com a presença da icterícia e de abdômen distendido. Ansiedade, comportamentos agressivos e medo estão presentes, muitas vezes associados às repetidas crises de dor e internações s $^{1-2 ; 7-9}$.

Além disto, o retardo do desenvolvimento e do crescimento provocados pelas doenças falciformes faz com que o adolescente sofra ações preconceituosas e, muitas vezes, seja vítima de estigma e segregação social, principalmente no ambiente escolar. Todos estes fatores podem levar o adolescente portador de doença falciforme a não possuir um desempenho satisfatório de suas ocupações e papéis, quando comparado a adolescentes saudáveis?.

Diante disto, os objetivos deste trabalho foram descrever e analisar a percepção dos adolescentes sobre o viver com a doença falciforme; identificar e analisar quais os principais papéis ocupacionais de adolescentes com doença falciforme e a importância que atribuem a eles.

\section{PERCURSO METODOLÓGICO}

Trata-se de um estudo transversal descritivo com abordagem quantitativa qualitativa. Quantitativa, pois aos dados obtidos para caracterização dos sujeitos da pesquisa e de seus papéis ocupacionais foram atribuídos valores numéricos, sendo, posteriormente, submetidos a uma análise estatística ${ }^{10}$; e qualitativa, por meio de entrevista, que forneceu dados possíveis de se explorar o conjunto de opiniões sobre o viver com doença falciforme ${ }^{11}$. Os dados qualitativos foram transcritos, categorizados e analisados conforme a técnica de análise de conteúdo temático categorial proposta por Bardin ${ }^{12}$.

A amostra foi definida pelo critério de amostragem não probabilística de casos típicos ${ }^{13}$, caracterizando-se por um grupo de sete adolescentes com doença falciforme, que frequentam classe hospitalar no contra turno escolar em uma organização filantrópica que atende crianças e adolescentes portadoras de doença onco-hematológicas de uma microrregião no interior de Minas Gerais. Esta instituição tem por objetivo prestar atendimentos a crianças e adolescentes que possuem hemopatias, com carência familiar de recursos financeiros e outros, sendo realizado neste local atendimento psicológico e de assistência social, acompanhamento e/ou reforço escolar, atividades culturais e de lazer, sempre envolvendo também seus familiares.

Os critérios de inclusão para participação na pesquisa foram: ter idade compreendida entre 12 e 18 anos; ter doença falciforme e estar em acompanhamento na instituição no período da coleta de dados; ter autorização do responsável legal e concordar em assinar o Termo de Consentimento Livre e Esclarecido. Os critérios para exclusão da pesquisa foram a impossibilidade de participar devido a questões físicas no que se refere à realização das entrevistas e coleta 
de dados e a solicitação para sua retirada da pesquisa. A coleta de dados ocorreu entre os meses de março e abril de 2012.

No período da coleta de dados havia 10 adolescentes com doença falciforme cadastrados nas classes hospitalares. Todos foram convidados para participar da pesquisa, sendo que destes dois se recusaram e um saiu da instituição durante o período de coleta dos dados, totalizando sete sujeitos nesta pesquisa.

Os dados foram obtidos pela aplicação da Lista de Identificação de Papéis Ocupacionais, pelo Critério de Classificação Econômica Brasil (CCEB) e por uma entrevista semiestruturada realizada a partir de um roteiro de entrevista elaborado pelas autoras, que abordou conteúdos relativos à cor da pele, tipo da doença, escolaridade dos adolescentes e dos seus pais, renda mensal média, número de moradores e quantos destes trabalham, além de conter a questão norteadora: "Gostaria que me falasse como é para você, adolescente, viver com a doença falciforme". A entrevista possibilitou que os adolescentes discorressem sobre o tema abordado, entretanto sem permitir que se esquivassem do objetivo proposto.

A Lista de Identificação de Papéis Ocupacionais é um instrumento válido e confiável de avaliação que tem a finalidade de extrair informações a respeito dos papéis ocupacionais de uma pessoa. Fornece dados sobre a percepção do individuo quanto à sua vida, dados referentes ao grau de importância de cada papel e informação complementar sobre a capacidade de uma pessoa em manter o equilíbrio entre os papéis ${ }^{14}$. Os papéis ocupacionais consistem em comportamentos produtivos ou de lazer. Tais papéis organizam o comportamento contribuindo para a identidade pessoal dos indivíduos, conduzindo as expectativas sociais a uma realização, organizando o uso do tempo e envolvendo os indivíduos na estrutura social ${ }^{14}$.

As pesquisadoras realizaram treinamento para utilização da Lista de Identificação de Papéis Ocupacionais e esta foi previamente autorizada por sua autora.

O Critério de Classificação Econômica Brasil tem a função de estimar o poder de compra das pessoas e famílias urbanas, não classificando a população em termos de "classes sociais", mas como "classes econômicas".

Os dados obtidos pela entrevista foram transcritos e analisados pelo método de análise de conteúdo temático categorial, proposto por Bardin ${ }^{12}$, obtendo-se cinco categorias temáticas.

Este estudo teve aprovação do Comitê de Ética em Pesquisa da Universidade Federal do Triângulo Mineiro, de acordo com o parecer número 2012/11.

\section{RESULTADOS E DISCUSSÕES}

Participaram da pesquisa sete adolescentes sendo três meninos e quatro meninas com média de idade de 14,5 anos, pretos e pardos. Com relação à doença falciforme seis adolescentes são SS e um adolescente é SC, conforme mostra a Tabela 1.

Tabela 1 - Caracterização dos sujeitos, por forma de doença falciforme, sexo, idade, cor da pele e escolaridade

\begin{tabular}{rccccc}
\hline Sujeito & Doença falciforme & Sexo & Idade & Cor da pele & Escolaridade \\
\hline S1 & SS & M & 17 & Preta & $4^{\circ}$ ano \\
S2 & SC & F & 15 & Preta & $1^{\circ}$ ano* \\
S3 & SS & M & 17 & Preta & $7^{\circ}$ ano \\
S4 & SS & F & 12 & Parda & $5^{\circ}$ ano \\
S5 & SS & P & 12 & Preta & $4^{\circ}$ ano \\
S6 & SS & F & 15 & Preta & $9^{\circ}$ ano \\
S7 & SS & F & 14 & Parda & $7^{\circ}$ ano \\
\hline *É
\end{tabular}

Tabela 2 - Caracterização Socioeconômica

\begin{tabular}{|c|c|c|c|c|c|}
\hline Sujeito & $\begin{array}{c}\text { Classe } \\
\text { econômica }\end{array}$ & $\begin{array}{l}\text { Renda mensal } \\
\text { média (R\$) }\end{array}$ & $\begin{array}{c}\mathrm{N}^{0} \text { de moradores que } \\
\text { trabalham }\end{array}$ & Escolaridade (Mãe) & Escolaridade (Pai) \\
\hline S1 & $\mathrm{C} 2$ & $1.244,00$ & 0 & $3^{\circ}$ ano & (Falecido) \\
\hline S2 & $\mathrm{C} 1$ & $2.000,00$ & 1 & $4^{\circ}$ ano & $6^{\circ}$ ano \\
\hline $\mathbf{S 3}$ & B2 & $3.000,00$ & 3 & $7^{\circ}$ ano & $8^{\circ}$ ano \\
\hline S4 & $\mathrm{C} 2$ & 800,00 & 1 & $5^{\circ}$ ano & $4^{\circ}$ ano \\
\hline S5 & $\mathrm{B} 1$ & Não informou & 4 & $4^{\circ}$ ano & $7^{\circ}$ ano \\
\hline S6 & $\mathrm{C} 1$ & 980,00 & 1 & $4^{\circ}$ ano & $5^{\circ}$ ano \\
\hline S7 & $\mathrm{C} 1$ & $1.300,00$ & 2 & $3^{\circ}$ ano* & $9^{\circ}$ ano \\
\hline
\end{tabular}

* Ensino médio. Os outros equivalem ao ensino fundamental. 
Em relação à classificação econômica, as famílias dos adolescentes enquadraram-se entre B1 a C2. A renda mensal média foi de dois salários mínimos, para cerca de seis moradores por residência, sendo que cerca de dois destes trabalham, conforme apresenta a Tabela 2.

Estudos apontam que, no Brasil, a doença falciforme ocorre predominante entre os negros (pretos e pardos), devendo-se atentar ao fato de que, principalmente devido à miscigenação em nosso país, não é exclusiva destas populações. Tendo em visto as disparidades relacionadas aos estratos sociais e econômicos no país, com predomínio de negros em grupos com menos educação e mais pobres, as doenças falciformes tornam-se comuns nestes grupos sociais devendo ser consideradas do ponto de vista da saúde pública $^{15-16}$.

Em relação à caracterização sociodemográfica dos adolescentes, observa-se pelos dados apresentados nas Tabelas 1 e 2 que eles estão, em sua maioria, atrasados com relação ao ano escolar. Em relação aos pais, apenas uma mãe completou o $2^{\circ}$ grau, sendo que a maior parte dos pais possui ensino fundamental incompleto. Estes resultados vêm ao encontro de diversas pesquisas, como a realizada por Barreto e Cipolotti ${ }^{18}$, que obtiveram que a maioria dos portadores da doença estava com idade defasada para a série, ou seja, possuíam idade superior em no mínimo dois anos àquela recomendada para a série em qual se encontravam e, entre os cuidadores, a maior parte relatou não ter ensino fundamental completo. A baixa escolaridade tem influência na renda mensal, pela maior susceptibilidade a empregos informais.

A partir dos dados apresentados na Tabela 2, observa-se a fragilidade socioeconômica vivenciada pelos adolescentes e suas famílias. Embora os sujeitos da pesquisa tenham sido selecionados em uma instituição que tem como requisito além da hemopatia a carência da população atendida, a literatura aponta que grande parte dos portadores de doença falciforme pertence às camadas desfavorecidas economicamente, fato que interfere no acesso e na qualidade da atenção integral. Sabe-se que a baixa renda gera uma saúde mais precária e por sua vez, uma saúde insatisfatória pode resultar em rendas mais baixas. Isto pode ser agravado devido à maior prevalência entre a população negra, que muitas vezes é submetida ao preconceito racial. Assim sendo, para a realização de políticas eficazes para provisão de saúde deve-se haver uma associação direta com políticas de combate à pobreza e à desigualdade social e racial ${ }^{15 ; 17}$.

Com relação à distribuição dos papéis ocupacionais ao longo do tempo, os sete adolescentes trouxeram que os papéis mais realizados no passado foram os de amigo e membro de família. Os principais papéis realizados no presente por todos eles são os de estudante, amigo e membro de família. Destacam-se para os sete adolescentes como papéis pretendidos de se realizar no futuro os de estudante, trabalhador, cuidador, amigo, membro de família e passatempo/amador, conforme mostra a Tabela 3.

Tabela 3 - Distribuição dos papéis ocupacionais ao longo do tempo

\begin{tabular}{|c|c|c|c|}
\hline Papéis Ocupacionais & Passado & Presente & Futuro \\
\hline Estudante & $86 \%$ & $100 \%$ & $100 \%$ \\
\hline Trabalhador & $29 \%$ & $29 \%$ & $100 \%$ \\
\hline Voluntário & $29 \%$ & $29 \%$ & $57 \%$ \\
\hline Cuidador & $71 \%$ & $86 \%$ & $100 \%$ \\
\hline Serviço Doméstico & $57 \%$ & $86 \%$ & $29 \%$ \\
\hline Amigo & $100 \%$ & $100 \%$ & $100 \%$ \\
\hline Membro de Família & $100 \%$ & $100 \%$ & $100 \%$ \\
\hline Religioso & $86 \%$ & $57 \%$ & $86 \%$ \\
\hline Passatempo/Amador & $71 \%$ & $86 \%$ & $100 \%$ \\
\hline Part. em Organizações & $0 \%$ & $0 \%$ & $0 \%$ \\
\hline
\end{tabular}

Em relação à distribuição do grau de importância dos papéis ocupacionais para os adolescentes, obteve-se que os principais papéis considerados como de nenhuma importância foram os de serviço doméstico, sendo este referido por 4 adolescentes e participante em organizações, citado por 3 dos sujeitos; destaca-se como considerado de alguma importância para 4 dos adolescentes o papel de voluntário e os considerados como de muita importância para todos os sujeitos os de estudante e membro de família, conforme apresenta a Tabela 4. 
Marques LN, et al. O viver com a doença falciforme: percepção de adolescentes. Rev Ter Ocup Univ São Paulo. 2015 jan./abr.;26(1):109-17.

Tabela 4 - Distribuição do grau de importância dos papéis ocupacionais

\begin{tabular}{lccc}
\hline Papéis Ocupacionais & Nenhuma importância & Alguma importância & Muita importância \\
\hline Estudante & $0 \%$ & $0 \%$ & $\mathbf{1 0 0 \%}$ \\
Trabalhador & $0 \%$ & $14 \%$ & $86 \%$ \\
Voluntário & $0 \%$ & $57 \%$ & $43 \%$ \\
Cuidador & $0 \%$ & $14 \%$ & $86 \%$ \\
Serviço Doméstico & $57 \%$ & $14 \%$ & $29 \%$ \\
Amigo & $0 \%$ & $14 \%$ & $86 \%$ \\
Membro de Família & $0 \%$ & $0 \%$ & $\mathbf{1 0 0 \%}$ \\
Religioso & $0 \%$ & $14 \%$ & $86 \%$ \\
Passatempo/Amador & $14 \%$ & $0 \%$ & $86 \%$ \\
Part. em Organizações & $43 \%$ & $14 \%$ & $43 \%$ \\
\end{tabular}

Como pode ser percebido na análise dos dados da Lista de Identificação de Papéis Ocupacionais, observa-se que, apesar do atraso escolar e indisciplina apresentado pela maioria dos adolescentes, todos eles referiram ser estudante um papel importante, almejando desenvolver este papel no futuro. Ser estudante é comumente importante para o adolescente, pois prepara o indivíduo com as habilidades educacionais necessárias para a transição bem sucedida para a força de trabalho adulto e fornece oportunidades para se relacionarem em sociedade, permitindo o ajuste para os sucessos e para as falhas em relacionamentos sociais que influenciarão fortemente seu desenvolvimento ${ }^{19}$.

O papel de amigo foi considerado de grande importância por seis participantes, sendo um dos papéis continuo ao longo da vida (passado, presente, futuro), equiparando-se ao papel de membro de família, o qual foi destacado como de grande importância para todos os entrevistados.

Para os adolescentes entrevistados, o papel de amigo é desempenhado principalmente na instituição onde foi realizada a pesquisa, onde os "melhores amigos" são também portadores da doença falciforme. Papalia et al. ${ }^{20}$ relatam que a intensidade e a importância das amizades e a quantidade de tempo gasta com os amigos são provavelmente maiores na adolescência do que em outras fases da vida, sendo essa amizade uma fonte importante de apoio emocional durante a complexa transição da adolescência, de afeto, simpatia, entendimento e orientação moral, sendo que a escolha destes amigos é realizada por meio da semelhança entre eles, seja ligada a raça/etnia, gênero, ou outros.

Amigos, familiares e pessoas próximas fornecem o suporte social necessário durante a vida do portador de doença falciforme, tendo grande importância para estes indivíduos. Este suporte social faz com que os adolescentes sejam habilitados a lidar com estressores ambientais, podendo aumentar a sua expectativa de autoeficácia e, portanto, o seu grau de autonomia frente à doença e ao tratamento e consequente melhora de sua qualidade de vida $^{2 ; 21}$.

O papel de trabalhador foi destacado como pretendido para o futuro por todos os adolescentes, tendo sido mais citado pelos adolescentes com 17 anos, tendo em vista que a adolescência constitui-se em um período no qual ocorre transição para a vida adulta e de trabalho. Entretanto, relataram o medo do desemprego, relacionado com a frequência de crises de dor, pela baixa escolaridade e estigma/preconceito.

A ausência de interesse pelo papel de serviços domésticos pode se justificar pela presença do medo do aparecimento de dor, principalmente devido à limitação para a realização de atividades que exigem a ação de pegar e/ou carregar peso ou demandam uso de água fria, que favorece o aparecimento de quadro álgico ${ }^{22}$.

Com relação ao papel de membro de organizações, este não teve destaque para nenhum dos adolescentes, nem quanto à sua importância, nem quanto à pretensão de realizar este papel no futuro, o que pode ser devido a esse não ser um interesse comum na adolescência.

A partir da questão norteadora "Gostaria que me falasse como é para você, adolescente, viver com a doença falciforme" feita aos entrevistados, obtiveram-se cinco categorias temáticas através da semelhança entre os discursos dos adolescentes, sendo estas:

vivendo com a dor; a importância do autocuidado no viver com doença falciforme; o viver sem a educação física/ atividade física; o viver com a superproteção materna; e o viver com a falta de informação de familiares e amigos/ 
parceiro afetivo acerca da doença.

Com relação à categoria "O viver com dor", os adolescentes destacam a dor no viver com a doença falciforme, descrita como a principal responsável por hospitalizações frequentes, absenteísmo escolar e limitação de atividades física e de lazer, o que leva a grande sofrimento. Os relatos de cinco adolescentes apontaram o fato de muitas vezes não conseguirem dimensionar com, precisão, a extensão e a localização da dor:

Tenho dor, no corpo todo, subindo assim “Ó”, do peito até nas "costas". (S1)

Quando eu tenho crise normalmente é por dor, muita dor no corpo todo, geral. (S2)

Tem hora assim... Tem hora que é bom pra "nóis não ir" pra escola, né? Aí tem hora que é ruim, porque "sente" dor nas pernas, dor de cabeça, dor nos braço... (S4)

De vez em quando eu vou respirar parece que tem uma coisa fincando no meu coração, dói. (...) Quando eu tenho crise é muito também por dor nos ossos, no corpo todo. (S5)

A gente sente mais dor (...). Quando eu interno é mais por causa da dor mesmo. (S6)

A dor crônica em adolescentes com doença falciforme é muito comum, sendo que estes muitas vezes perdem a capacidade de dimensionar, com precisão, a extensão de sua dor, podendo haver implicações negativas na qualidade de vida, como prejuízo da convivência social, perda da libido, ausência do sono, perda da autoestima e ausência de aspirações de vida para o futuro ${ }^{17}$. A experiência da dor crônica leva o indivíduo a alterar seus hábitos de vida, influenciando na escolha e desempenho de papéis ocupacionais, ocasionando problemas de ordem econômica, social e emocional ${ }^{2}$.

$\mathrm{Na}$ categoria "A importância do autocuidado no viver com doença falciforme", cinco dos adolescentes reconhecem a importância do autocuidado visando ter uma vida satisfatória e referem que este autocuidado é voltado principalmente para a prevenção das manifestações clínicas da doença, incluindo ações como evitar beber álcool, não nadar em água gelada e agasalhar-se adequadamente.

Eu tenho a vida normal, mas eu tenho que tomar cuidado, né? Não posso tomar friagem, não posso fazer muito esforço, é, tenho que tomar meus medicamentos corretos. (S7)

Não pode beber álcool, de jeito nenhum. É...ficar muito tempo no sereno não pode fora, frio não pode tomar... mudança de temperatura é o que mais faz eu ter crise.” (S3)

Eu não posso correr muito porque dá dor nas pernas. Só correr. (S4)

Assim, andar de bicicleta pra você é ir ali, ali e voltar. Pra mim, se eu for só ali já cansa, ai eu tenho que parar, respirar, beber uma água, ai depois eu tenho que ir. (S6)

O que eu não posso é tomar banho em água gelada, nadar em água gelada. De vez em quando, só quando o sol tá quente, aí minha mãe deixa. Quando tá frio eu nem faço nada, nada mesmo. (S5)

Porém este cuidado com a saúde e o corpo não é, muitas vezes, praticado por eles, como observado na fala de duas das entrevistadas:

Eles falam assim, que dá crise se eu tomar muita friagem quando muda o tempo e não se agasalhar, (...) Tem que tomar os remédios, e tudo. Mas pra falar a verdade (...) eu tinha que tomar semanalmente, todo dia, até o resto da vida, mas eu não tomo não. Aí eu fico um mês sem tomar (risos). Mas assim, não tá dando mais crise em mim, entende? Mas eu sei que eu tenho que tomar e tenho que continuar tomando. (S2)

Eu fico direto tomando água gelada, direto, direto mesmo. Ai depois, eu fico na rua, a noite, na friagem. Ai é mais fácil de eu pegar algum trem. (S6)

O Ministério da Saúde ${ }^{6}$ refere que o maior desafio do profissional da saúde no atendimento voltado ao adolescente com doença falciforme é manter a adesão do jovem ao regime de tratamento e às praticas de autocuidado, o que pode ser dificultado por características normais para esta fase da vida, como a crise de identidade do adolescente e dificuldade de relacionamento dele com os pais. Isto pode levar a maior ocorrência de manifestações clínicas da doença e causar prejuízos na qualidade de vida dessas pessoas.

$\mathrm{Na}$ terceira categoria, "O viver com a doença falciforme na escola", observa-se o desinteresse dos adolescentes pela escola e atividades escolares, sendo que quatro dos adolescentes estão em atraso escolar.

Tô na $4^{a}$ série "causo" que eu faço muita bagunça dentro da sala. Eu gosto é de fazer bagunça. (S1)

Eu reprovei na quarta série. (S4)

$\mathrm{O}$ ano passado eu parei a escola por causa de briga, ai eu fui expulso, sai. (S3)

Tem hora assim... Tem hora que é bom pra "nós não ir" pra escola, né? (S4) 
Percebe-se a dificuldade da escola e dos professores em adaptarem o ensino a estes adolescentes, o que contribui para dificuldade no aprendizado e atraso escolar.

(...) quando eu tava assim na primeira, na segunda, "eles foi me passando" e eu acho que eu não sabia muita coisa (...) eu passei, fui passando, ai eu tenho muita dificuldade por causa disto, eu passei e fiquei internada, ai ninguém me ajudou, eu tive que correr atrás. (S6)

O não reconhecimento dos alunos com doença falciforme como alunos com necessidades médicas e educacionais específicas atrapalha o desenvolvimento escolar desse aluno, assim como sua formação profissional. De acordo com Paiva ${ }^{23}$, a falta de informação da comunidade escolar sobre a doença falciforme, o aparecimento de sinais e sintomas da doença, hospitalizações ou tratamento, em conjunto com a falta de atenção às suas necessidades escolares, devido às complicações que apresentam a nível biológico, psicológico e sociocultural, fazem com que os alunos portadores da doença falciforme tenham maiores chances para o absentismo escolar e desinteresse pela escola.

A categoria "O viver sem a educação física/ atividade física" foi definida a partir da fala de quatro adolescentes, que referiram não realizar a educação física e outras atividades relacionadas, como participação nas olimpíadas escolares, devido tanto ao medo da crise de dor pelos próprios adolescentes, quanto por recomendações da própria escola de não se realizar esta atividade básica escolar.

A educação física eu não faço "por causa que" é a noite e pode me dar crise. (S1)

Igual, na hora assim, do exercício físico, faz, mas fica lá, fica cansada, cansa mais do que as outras pessoas, entende? (S2)

$\mathrm{Na}$ hora da educação física eu fico conversando com os meus amigos. (...) Eu tenho nota, porque eu tenho atestado, (...) esse negócio assim de esporte eu não faço não. As Olimpíadas eu nem participo, fico lá na rua, eu vou pra ver os meninos e fico às vezes lá, olhando pra eles. (S6)

Atividade física assim eu não faço, porque assim, além da anemia eu tenho necrose no fêmur. Aí eu não posso fazer muito esforço por causa do meu fêmur. (S7)

Para prevenir o aparecimento da dor, algumas pessoas tendem a reduzir ao máximo sua participação em atividades físicas e, quando o medo da dor é a causa principal desta redução, pode-se estabelecer um ciclo vicioso que leva a deterioração da boa forma física e aumento da inatividade. Porém, os dados mostram uma grande vontade dos adolescentes em realizar atividades físicas, o que é esperado nesta faixa etária, sendo que a não realização das mesmas podem aumentar a sensação de inferioridade, levando-os a prejuízos psico comportamentais, que poderão se estender à fase adulta ${ }^{17}$.

Como os sintomas da doença podem ser desencadeados com esforço físico excessivo, muitos profissionais aconselham repouso e a não realização de atividades físicas, principalmente para pessoas com a anemia falciforme. Porém, indivíduos com doença crônica não são inválidos, podendo se beneficiar com o exercício e o desenvolvimento psicossocial e pessoal envolvido na realização da educação física, devendo ser encorajados a realizar estas atividades. Faz-se necessário que estas sejam regulares, moderadas e o esforço progrida lentamente, sendo o monitoramento do esforço físico realizado pelo próprio adolescente, além de haver a necessidade de se atentar para cuidados básicos para que se possa evitar o aparecimento de crises de dor ${ }^{24}$.

A categoria "O viver com a superproteção materna" revela a superproteção familiar, destacada pela figura materna, relatada por três dos adolescentes.

Meus pais ainda me superprotegem mas assim, com muito menos proteção, entende? (...) Porque assim, eu não to precisando muito da atenção agora, mas precisa né? (...) Mas eles não me deixam sair. (S2)

Minha mãe que fica mais em cima de mim, não deixa eu fazer muita coisa. (S5)

Não saio, minha mãe não deixa. (S4)

Rodrigues $^{25}$ aponta que os pais de crianças com doença crônica podem, por sentir raiva, culpa e tristeza pela imperfeição do filho, não oferecer assistência física constante, negligenciando-o. Mas pode ocorrer o contrário por meio da superproteção, sendo impostos limites às iniciativas de autonomia e privação do sentimento de competência. As mães evitam, ao máximo, qualquer possibilidade de separação do filho com doença crônica, desencadeando sentimentos profundos de preocupação e medo de perdê-lo, demonstrando forte vínculo mãe-filho. No entanto, esta interação inadequada pode levá-lo a ter maiores riscos de atraso e/ou dificuldades no desenvolvimento, limitações sociais e de papéis ocupacionais.

$\mathrm{Na}$ categoria "O viver com a falta de informação de familiares e amigos/parceiro afetivo acerca da doença", três adolescentes relataram sobre o desconhecimento de amigos, colegas da escola e parceiros afetivos e até mesmo por familiares, como o pai, sobre a doença falciforme. Porém, percebe-se que este desconhecimento é reforçado por meio da não explanação sobre a doença por parte do próprio 
adolescente portador.

Eu acho que pouca gente sabe o que é anemia falciforme. Acho que meus amigos nem sabem, tipo, meus amigos da escola. Eu falo mais ou menos pra alguns. (S5)

Eu já tive namorado e ele não soube. Porque eu não falava nada, né? (...) Alguns dos meus amigos sabem que eu tenho doença falciforme, outros não, entende? Porque eu não gosto de ficar falando. (...) o povo da minha família (...) eu acho que, sabe, mas sabe assim por cima. Não sabe aquela coisa, o que é MESMO, entende? Eu e minha mãe, a gente sabe bem, mas se você perguntar um negocinho pro meu pai, assim, eu acho que ele não vai saber te responder (risos) direito. (S2)

Eu só tenho um amigo que sabe que tenho anemia falciforme. (S1)

Em adolescentes com doença crônica a comunicação com amigos e pessoas próximas é afetada, de modo que a revelação pelos adolescentes de conteúdos íntimos é diminuída e as conversações sobre conteúdos ligados à enfermidade acabam também sendo evitadas por eles ${ }^{26}$. O apoio social dado a este adolescente, por outro lado, é consideravelmente aumentado, o que altera a reciprocidade, base das relações de amizade.

\section{CONSIDERAÇÕES FINAIS}

Conclui-se que o viver dos adolescentes com doença falciforme participantes desta pesquisa é rodeado de privações, que se manifestam muitas vezes pela realização inadequada e/ou não realização de papéis ocupacionais esperados para esta fase da vida, seja devido a manifestações clínicas da doença, sendo destacada a presença de dor crônica; por medo de piora da doença; por superproteção familiar; por preconceito, estigma e/ou falta de informações sobre a doença falciforme por familiares, amigos e profissionais da saúde, educação ou assistência social. Estas privações ocorrem em vários espaços de viver do adolescente e podem levá-lo a qualidade de vida insatisfatória e repercussões negativas no futuro.

\section{REFERÊNCIAS}

1. Grossman E. Assistência ao adolescente portador de doença crônica. In: Brasil. Ministério da Saúde. Secretaria de Atenção à Saúde. Departamento de Ações Programáticas Estratégicas. Saúde do adolescente: competências e habilidades. Brasília:
A origem racial da doença falciforme, seu predomínio entre negros e a associação desta doença à baixa escolaridade e renda, presentes em diversos trabalhos, demonstram a necessidade do desenvolvimento de estratégias públicas, não só em relação à saúde, como também na educação e nas condições econômicas dessas famílias, visando melhor manejo e controle da doença. Para se pensar em saúde, devem-se levar em consideração as condições de existência e estilo de vida dos adolescentes observando a influência não só dos fatores biológicos, mas a de todos os contextos do indivíduo que em conjunto influenciam as condições de vida e as formas de viver.

Especialmente para a Terapia Ocupacional é relevante para a realização de uma boa atuação com essa população, que atenda as reais necessidades da pessoa; é imprescindível conhecer suas peculiaridades e dificuldades, sendo fundamental ouvir os relatos e histórias desta, não somente com relação à sua doença, mas ao significado que dão às suas vidas.

É necessário extrapolar o atendimento voltado ao adolescente com doença falciforme, saindo do atendimento hospitalar direcionando-se aos seus espaços de convivência e inserção, incluindo o enfoque em seus múltiplos contextos (físico, cultural, social) em seus múltiplos espaços (moradia, escola, praça de eventos e de lazer), visando diminuir o impacto negativo da doença falciforme em seu viver como adolescente. Para isto é imprescindível o desenvolvimento de abordagens e de estratégias com o enfoque na subjetividade, observando o adoecimento na perspectiva de quem está adoecendo.

Reconhece-se que os resultados descritos são específicos dos sujeitos da pesquisa, não sendo passível de generalizações ao contingente de adolescentes com doença falciforme.

Futuros estudos podem aprofundar a investigação sobre o viver de adolescentes com doença falciforme, contribuindo para uma constante reflexão e elaboração de estratégias de intervenção com esta população, uma adesão espontânea ao tratamento médico pelos adolescentes e a consequente promoção da qualidade de vida dessas pessoas.

Editora do Ministério da Saúde; 2008. p.47-51. Disponível em: http://bvsms.saude.gov.br/bvs/publicacoes/saude adolescente_competencias_habilidades.pdf.

2. Pitaluga WVC. Avaliação da qualidade de vida de portadores 
de anemia falciforme [Dissertação]. Goiânia: Universidade Católica de Goiás; 2006. Disponível em: http://tede.biblioteca. ucg.br/tde_busca/arquivo.php?codArquivo=296.

3. Jesus JA. Doença falciforme no Brasil. Gaz Med Bahia. 2010;80(3):8-9. Disponível em: http://www.gmbahia.ufba.br/ index.php/gmbahia/article/viewFile/1102/1058.

4. Loureiro MM, Rozenfeld S. Epidemiologia de internações por doença falciforme no Brasil. Rev Saúde Pública. 2005;39(6):943-9. doi: S0034-89102005000600012.

5. Akinyanju O, Olujohungbe A. How to live with sickle cell disorder. 3rd ed. Nigéria: Book Builders; 2009.

6. Brasil. Ministério da Saúde. Secretaria de Atenção à Saúde. Manual de educação em saúde - v. 1: autocuidado na doença falciforme. Brasília; 2008. Disponível em: http://bvsms.saude. gov.br/bvs/publicacoes/manual_educacao_saude_volume1. pdf.

7. Pereira SAS, Cardoso CS, Brener S, Proietti ABFC. Doença falciforme e qualidade de vida: um estudo da percepção subjetiva dos pacientes da Fundação Hemominas, Minas Gerais, Brasil. Rev Bras Hematol Hemoter. 2008;30(5):411-6. doi: S1516-84842008000500015.

8. Felix AA, Souza HM, Ribeiro SBF. Aspectos epidemiológicos e sociais da doença falciforme. Rev Bras Hematol Hemoter. 2010;32(3):203-8. doi: s1516-84842010005000072.

9. Araújo PIC. O autocuidado na doença falciforme. Rev Bras Hematol Hemoter. 2007;29(3):239-46. doi: S151684842007000300010 .

10. Cozby PC. Métodos de pesquisa em ciências do comportamento. São Paulo: Atlas; 2003.

11. Minayo MCS. O desafio do conhecimento: pesquisa qualitativa em saúde. São Paulo: Hucitc-ABRASCO; 2008.

12. Bardin L. Análise do conteúdo. Lisboa: Edições 70; 2010.

13. Sampieri RH, Collado CF, Lucio PB. O processo de pesquisa e os enfoques quantitativos e qualitativos: rumo a um modelo integral. In: Sampieri RH, Collado CF, Lucio PB. Metodologia de pesquisa. 3a ed. São Paulo: McGraw-Hill; 2006. p.2-21.

14. Cordeiro JJR. Validação da lista de identificação de papéis ocupacionais em pacientes portadores de doença pulmonar obstrutiva crônica (DPOC) no Brasil [dissertação]. São Paulo: Universidade Federal de São Paulo, Escola Paulista de Medicina, Programa de Pós-graduação em Reabilitação; 2005. Disponível em: http://www.dominiopublico.gov.br/pesquisa/ DetalheObraForm.do?select_action=\&co_obra $=102441$.

15. Zago MA. Anemia falciforme e doenças falciformes. In: Brasil. Ministério da Saúde. Secretaria de Políticas de Saúde. Manual de doenças mais importantes, por razões étnicas, na população afrodescendente. Brasília: Ministério da Saúde; 2001.p.13-36. Disponível em: http://bvsms.saude.gov.br/bvs/publicacoes/ doencas_etnicas.pdf.

Recebido para publicação: 19/03/2013

Aceito para publicação: 12/11/2014
16. Ohara DG, Ruas G, CASTRO SS, Martins PRJ, Walsh IAP. Dor osteomuscular, perfil e qualidade de vida de indivíduos com doença falciforme. Rev Bras Fisioter. 2012;16(5):431-8. doi: S1413-35552012005000043.

17. Serafim ESS, Soares RM, Oliveira TMX, Soares MJNL. Capacitação de profissionais de saúde para o manejo da dor em adolescentes portadores de doença falciforme na atenção primária. Adolesc Saúde. 2011;8(4):55-8. Disponível em: http://www.adolescenciaesaude.com/detalhe_artigo. asp?id=296.

18. Barreto FJN, Cipolotti R. Sintomas depressivos em crianças e adolescentes com anemia falciforme. J Bras Psiquiatr. 2011;60(4):277-83. doi: S0047-20852011000400008.

19. Nonose ERS. Doenças crônicas na escola: um estudo das necessidades dos alunos [Dissertação]. Marília-SP: Faculdade de Filosofia e Ciências, Universidade Estadual Paulista "Júlio de Mesquita Filho"; 2009. Disponível em: http://www.marilia.unesp.br/Home/Pos-Graduacao/ Educacao/Dissertacoes/nonose_ers_me_mar.pdf.

20. Papalia DE, Olds SW, Feldman RD. Desenvolvimento psicossocial na adolescência. In: Papalia DE, Olds SW, Feldman RD. Desenvolvimento humano. 10a ed. Porto Alegre: Artmed; 2010. p.434-67.

21. Batista TF. Com(vivendo) com a anemia falciforme: o olhar da enfermagem para o cotidiano de adolescentes [dissertação]. Salvador: EEUFBA; 2008. Disponível em: http://www.ccadoentescola.faced.ufba.br/arquivos/ tatianafancobatista.pdf.

22. Segava NB, Cavalcanti A. Análise do desempenho ocupacional de crianças e adolescentes com anemia falciforme. Rev Ter Ocup Univ São Paulo. 2011;22(3):27988. doi: http://dx.doi.org/10.11606/issn.2238-6149. v22i3p279-288.

23. Paiva SD. Aluno falciforme: o paradoxo na inclusão escolar "Conhecer para melhor Atender" [Monografia]. Belém: Universidade Estadual Vale do Acaraú; 2007. Disponível em: http://www.aafesp.org.br/biblioteca/TCCSeTeses/ SONIA_DIAS_DE_PAIVA.pdf.

24. Braga JAP. Medidas gerais no tratamento das doenças falciformes. Rev Bras Hematol Hemoter. 2007;29(3):233-8. doi: S1516-84842007000300009.

25. Rodrigues CCM. Do impacto do diagnóstico à superação dos desafios: a mãe sendo-com a criança com doença crônica [Dissertação]. Campinas: Faculdade de Ciências Médicas, Universidade Estadual de Campinas; 2009. Disponível em: http://www.bibliotecadigital.unicamp.br/ document $/$ ?code $=000467750$.

26. Ferreira BES, Garcia A. Aspectos da amizade de adolescentes portadores de diabetes e câncer. Estud Psicol. 2008;259(2):293-301. doi: S0103-166X2008000200013. 